\title{
Risco de transmissão do vírus da raiva oriundo de sagui (Callithrix jacchus), domiciliado e semidomiciliado, para o homem na região metropolitana de Fortaleza, Estado do Ceará
}

\author{
Risks of transmitting rabies virus from captive domiciliary common marmoset (Callithrix \\ jacchus) to human beings, in the metropolitan region of Fortaleza, State of Ceará, Brazil
}

\section{Tereza D'ávila de Freitas Aguiar ${ }^{1}$, Edmara Chaves Costa $^{1}$, Benedito Neilson Rolim ${ }^{1}$, Phyllis Catharina Romijn ${ }^{2}$, Nélio Batista de Morais ${ }^{1}$ e Maria Fátima da Silva Teixeira ${ }^{1}$}

\section{RESUMO}

Introdução: Uma variante do vírus da raiva foi identificada em associação a casos de raiva humanos, no Estado do Ceará, transmitidos por saguis (Callithrix jacchus), primatas frequentemente criados como animais de estimação. Essa variante não apresenta proximidade antigênica ou relação genética com as variantes do vírus encontradas em morcegos e mamíferos terrestres das Américas. $\mathrm{O}$ objetivo do estudo foi avaliar os fatores de risco de transmissão do vírus da raiva oriundo de sagui (C.jacchus), criado como animal de estimação, para o homem na região metropolitana de Fortaleza, Ceará. Métodos: Foi aplicado um questionário estruturado aos criadores de saguis, residentes nos municípios de Aquiraz e Maranguape, Ceará, enfocando o manejo e a interação desses primatas com humanos. Para avaliação da ocorrência de antígenos rábicos, através do teste de imunofluorescência direta (IFD), foram coletadas amostras de saliva dos saguis domiciliados e semidomiciliados. Com base nos resultados obtidos desses espécimes, foram analisadas amostras de sistema nervoso central (SNC). Resultados: Na análise dos questionários, observou-se a proximidade dos criadores de saguis durante o manejo desses animais nos domicílios, bem como, seus conhecimentos limitados sobre a raiva, demonstrando haver risco quanto à transmissão do vírus. De 29 amostras de saliva de saguis reavaliadas, uma $(3,4 \%)$ apresentou reação de IFD positiva. De 11 amostras de SNC, três $(27,3 \%)$ apresentaram positividade. Conclusões: Os dados laboratoriais estão de acordo com os achados dos questionários, confirmando haver risco da transmissão do vírus da raiva devido à convivência de humanos com saguis (C. jacchus).

Palavras-chaves: Sagui. Callithrix jacchus. Vírus da raiva. Transmissão. Humanos.

\begin{abstract}
Introduction: In the State of Ceará, a new variant of the rabies virus was identified associated with cases of human rabies transmitted by common marmosets (Callithrix jacchus), which are frequently kept as pets. This new variant does not present antigenic proximity or genetic relationship to variants of the virus isolated from bats and terrestrial mammals from the American continent. The present study aimed to evaluate the risk factors of rabies virus transmission from common marmosets (C. jacchus) maintained as pets in the metropolitan region of Fortaleza, State ofCeará, Brazil, to human beings. Methods: A questionnaire focusing on animal management and interaction between humans and primates was applied to individuals who had marmosets in the municipalities of Aquiraz and Maranguape. In order to evaluate the presence of rabies antigens by direct immunofluorescence test (DIF), samples of saliva were collected from domiciliary captive marmosets. Based on the detection of rabies antigens, biopsy samples of central nervous system (CNS) were analyzed. Results: Analysis of questionnaire data verified that a close relation exists between humans and their pet marmosets, especially during management practices. Additionally, these people showed minimal knowledge regarding rabies, which represents a greater risk of infection. Of the 29 saliva samples evaluated, one (3.4\%) was positive for DIF reaction and of the 11 CNS samples, three (27.3\%) were positive. Conclusions: Laboratory data are in agreement with the questionnaire findings, which confirm an increased risk of rabies virus transmission due to the close relation between humans and marmosets.
\end{abstract}

Keywords: Common marmoset. Callithrix jacchus. Rabies virus. Transmission. Humans.

1. Laboratório de Virologia, Universidade Estadual do Ceará, Fortaleza, CE. 2. Laboratório de Virologia, Empresa de Pesquisa Agropecuária do Rio de Janeiro, Rio de janeiro, RJ.

Endereço para correspondência: Drª Tereza D'ávila de Freitas Aguiar. LABOVIR/UECE. Av. Paranjana 1700, Campus do Itaperi, 60742-000 Fortaleza, CE.

Telefax: 5585 3101-9849

e-mail: labovirfavetuece@yahoo.com.br

Recebido para publicação em 01/06/2010

Aceito em 11/01/2011

\section{INTRODUÇÃO}

A raiva é uma doença infectocontagiosa, que acomete todos os animais de sangue quente, é causada por vírus neurotrópicos que atuam no sistema nervoso central (SNC), provocando uma encefalomielite aguda e quase sempre fatal, resultante principalmente da transmissão do vírus pela mordedura do animal infectado ${ }^{1}$.

Na saúde pública, a raiva é tida como uma grave zoonose, sendo classificada conforme seu ciclo epidemiológico e seu mecanismo de transmissão, em raiva urbana, silvestre e rural $^{2}$. A raiva envolvendo animais silvestres é um perigo constante para o homem e para os animais domésticos. Quando são acometidos pela raiva, os animais silvestres se aproximam das habitações e podem agredir o ser humano e animais domésticos ${ }^{3}$. Os principais reservatórios silvestres dos vírus da raiva no Brasil determinam quatro vertentes de maior relevância para a saúde pública, na atualidade, com respeito à raiva silvestre. Esses reservatórios incluem a raposa (Cerdocyon thous), o sagui (Callithrix jacchus), o morcego hematófago (Desmodus rotundus) e outras 40 espécies de quirópteros ${ }^{4,5}$.

Apesar das restrições determinadas por lei para a criação de animais silvestres em cativeiro, atualmente vem crescendo nos grandes centros urbanos brasileiros, o hábito de se criar animais silvestres como animais de estimação e, dentre os mamíferos, os saguis são exemplares muito cobiçados, o que é possível de constatação pela presença frequente desses animais nas campanhas de vacinação antirrábica destinadas somente a cães e gatos ${ }^{6}$.

O sagui de tufo branco, C. jacchus, é um pequeno primata de hábitos diurnos que se alimenta, na natureza, de insetos, pequenos vertebrados, frutas, ovos e exsudato de plantas ${ }^{7}$. Membros dessa espécie têm sido, há anos, atração popular em circos e zoológicos, por sua semelhança comportamental e física com o homem, e tornaram-se também, 
populares como animais de estimação. Porém, são transmissores de diversas enfermidades e o seu convívio com o ser humano é extremamente arriscado, pois são animais susceptíveis a doenças comuns ao homem e, assim, representam risco potencial para a saúde pública ${ }^{8}$.

No Estado do Ceará, é comum a identificação de saguis (C.jacchus) criados como animais de estimação, tendo sido registrados inúmeros casos de agressões, sendo esses animais responsáveis por onze casos de raiva humana no período de 1990 a $2010^{9,10}$. Em associação a casos notificados de raiva humana transmitidos por saguis, foi identificada uma variante do vírus da raiva, sem proximidade antigênica ou qualquer relação genética conhecida com as variantes do vírus da raiva encontradas em morcegos ou mamíferos terrestres das Américas?.

Ainda no período de 1990 a 2010, foram relatados 35 casos de raiva em saguis (C. jacchus) no Estado do Ceará ${ }^{10,11}$. Nesse estado, os saguis representam grande problema em relação a raiva silvestre ${ }^{12}$.

Portanto, nesse trabalho, os autores tiveram como objetivo avaliar os fatores de risco de transmissão do vírus da raiva oriundo de sagui (C. jacchus), criado como animal de estimação, para o homem na região metropolitana de Fortaleza, no Estado do Ceará.

\section{MÉTODOS}

\section{Fase exploratória}

Foram identificadas residências onde o sagui ( $C$. jacchus) era criado como animal doméstico, através de um boletim de cadastro de criadores de animais silvestres fornecido pela Secretaria de Saúde do Estado do Ceará ${ }^{13}$. O contato com os estabelecimentos identificados deu-se por meio de visitas. As áreas inclusas na pesquisa foram os municípios de Aquiraz e Maranguape na região metropolitana de Fortaleza, Estado do Ceará

Os sujeitos da pesquisa foram proprietários de saguis, estabelecendo-se uma amostra não probabilística do tipo intencional. Os critérios de inclusão dos participantes compreenderam a criação desses animais de interesse e a concordância em tomar parte da entrevista, enquanto o critério de exclusão baseou-se na discordância em participar da pesquisa.

O instrumento de investigação foi um questionário estruturado constituído por perguntas referentes aos dados gerais dos informantes e sobre o modo de criação do sagui como animal doméstico, enfocando a forma de manejo desse animal e se o mesmo tem contato próximo com humanos.

O questionário foi submetido ao pré-teste, visando-se identificar falhas metodológicas passíveis de existir nesse tipo de instrumento. O pré-teste foi executado com dois proprietários de saguis, sendo um residente em cada município do estudo. Após a tabulação, o questionário foi reformulado, tendo em vista o seu aprimoramento e o aumento de sua valide $z^{14}$. Os resultados definitivos dos questionários foram compilados em um banco de dados do programa Excel, organizados e apresentados na forma de gráficos e tabelas, sendo agrupados para a realização de análise descritiva dos elementos sobre investigação.

Foram considerados nessa pesquisa, os referenciais básicos da Bioética, baseados nos pressupostos da autonomia, não-maleficência, beneficência e justiça, de observância obrigatória, nos casos de investigações de cunho científico com participantes humanos.
Por ocasião da entrevista, foi apresentado aos participantes o Termo de Consentimento Livre e Esclarecido, cujo teor abrange esclarecimentos a cerca da natureza da pesquisa, voluntariedade da participação e garantia do sigilo concernente às informações coletadas.

\section{Método para trabalhar com os animais}

As manipulações realizadas com os saguis seguiram as normas determinadas pelos órgãos competentes, havendo autorização do IBAMA para coleta de amostras biológicas. $\mathrm{O}$ método para trabalhar com os animais baseou-senas diretrizes ministradas em treinamentos de Vigilância da Raiva Silvestre realizados, anualmente, entre 2002 e 2006.

\section{Coleta das amostras}

Os saguis foram manipulados com luvas de raspa de couro e os membros da equipe presentes, durante a coleta, utilizaram todos os equipamentos de proteção individual(EPI's).Para contenção física dos saguis semidomiciliados, foram utilizadas gaiolas-armadilha e puçás.

Para a coleta das amostras de saliva, os saguis (C. jacchus) foram imobilizados tanto física como quimicamente. Para a imobilização química, foi utilizado o isômero levógiro da cetamina na dose de $0,2 \mathrm{mg} / \mathrm{kg}$ para analgesia e até $5 \mathrm{mg} / \mathrm{kg}$ para indução anestésica, por via intramuscular. Em alguns animais, foi necessária a utilização da associação com o cloridrato de xilazina, na dose de $0,5 \mathrm{mg} / \mathrm{kg}$, por via intramuscular ${ }^{15}$.

\section{Amostras de saliva}

Foram coletadas amostras de saliva de saguis (C. jacchus) domiciliados e semidomiciliados nos municípios de Aquiraz e Maranguape na região metropolitana de Fortaleza no Estado do Ceará. Para a coleta, foram utilizados swabs e foi realizada a raspagem do assoalho da cavidade bucal do animal, sendo em seguida armazenado em tubos eppendorf contendo TRIzol ${ }^{\circledast}$.

A coleta de saliva dos saguis foi realizada em dois momentos. No primeiro, as residências referentes ao estudo foram visitadas para a realização da coleta.

O segundo momento, cinco meses após o primeiro, deu-se com o maior objetivo da execução da fase exploratória do estudo, onde todas as residências foram revisitadas. Foi então aproveitado o momento para realizar novamente a coleta de saliva dos saguis.

\section{Amostras de sistema nervoso central}

Com base nos resultados da análise das amostras de saliva dos saguis, positivas para a raiva no teste de imunofluorescência direta (IFD), os respectivos animais foram recolhidos por funcionários treinados da Secretaria de Saúde do Estado do Ceará, com o objetivo de realizar a confirmação da positividade, sendo eutanasiados para a coleta de amostras de SNC e análise para a presença de antígenos da raiva através da técnica de IFD.

O material coletado, tanto de saliva quanto de SNC, foi embalado de acordo com as normas de biossegurança ${ }^{16}$, e transportado, sob refrigeração de 2 a $8^{\circ} \mathrm{C}$, em veículo exclusivo da Secretaria de Saúde do Estado, ao Laboratório de Virologia da Universidade Estadual do Ceará.

Chegando ao laboratório, as amostras foram armazenadas a $-20^{\circ} \mathrm{C}$, em freezer exclusivo para diagnóstico da raiva e, posteriormente, foram analisadas, através da técnica de imunofluorescência direta.

\section{Imunofluorescência direta}

Os procedimentos que foram empregados no preparo e leitura das lâminas, tanto das amostras de saliva quanto de SNC, submetidas ao teste de IFD, seguiram, basicamente, as diretrizes preconizadas por 
Dean $\operatorname{cols}^{17}$ com as alterações no período de incubação do conjugado propostas por Roehe cols ${ }^{18}$, ao invés da incubação por $30 \mathrm{~min}$, foi utilizado um período maior, de $2 \mathrm{~h}$. O intuito foi o de se obter uma fluorescência de intensidade sensivelmente maior em relação ao método padrão recomendado, bem como, possibilitar, segundo os autores, uma completa inibição da fluorescência sobre os controles.

A leitura da reação foi executada no microscópio binocular de imunofluorescência da marca Zeiss, equipado com uma lâmpada de vapor de mercúrio HBO 50, filtro excitador VGI e filtro barreira Zeiss 43, no aumento de 400X em campo escuro.

Cada impressão foi examinada independentemente e classificada por dois observadores sob sistema duplo-cego, considerando-se a modalidade de controle de bias de mensuração ${ }^{19}$. Na ocorrência de desacordo frente aos critérios de classificação, os respectivos casos foram reexaminados no intuito de se estabelecer um consenso.

\section{Considerações éticas}

Esse projeto de pesquisa foi apreciado pelo Comitê de Ética em Pesquisa (CEP/UECE) e Comissão de Ética para o Uso de Animais da Universidade Estadual do Ceará (CEUA/UECE), sendo aprovado, sob os números de processos 09230145-2 e 092301479/63, respectivamente, estando de acordo com as disposições da Resolução n 196 de 10 de outubro de 1996 do Conselho Nacional de Saúde ${ }^{20}$, responsável pela deliberação de diretrizes e normas aplicadas à pesquisa com seres humanos e com os Princípios Éticos de Experimentação Animal.

\section{RESULTADOS}

\section{Perfil biossóciodemográfico dos criadores de sagui (Callithrix jacchus)}

A partir do boletim de cadastro de criadores de animais silvestres, foram identificadas 19 residências onde o sagui (C.jacchus) era criado como animal de estimação, distribuídas quase que homogeneamente entre os municípios de Aquiraz (47\%) e Maranguape (53\%), na região metropolitana de Fortaleza, no Estado do Ceará.

Foram realizadas entrevistas com os 19 chefes de família dos domicílios, utilizando como instrumento de trabalho um questionário estruturado. Nenhuma residência da pesquisa possuía menos de três habitantes e a presença do sagui, criado como animal de estimação foi mais frequente nos domicílios que possuíam três a cinco habitantes $11 / 19(57,9 \%)$. O número médio de habitantes por residência foi de cinco habitantes.

Mais da metade dos domicílios 10/19 (52,6\%) apresentava crianças. Essa questão é importante devido à maior facilidade de contato de crianças com os saguis, normalmente, na procura de diversão, representando um fator a mais de risco.

Durante a entrevista, foi questionado qual o maior grau de escolaridade dentre os habitantes de cada domicílio do estudo. $\mathrm{Na}$ maior parte dos domicílios, os criadores de saguis apresentavam baixo grau de instrução, sendo os mesmos analfabetos ou tendo apenas cursado o ensino fundamental incompleto, perfazendo $31 \%(6 / 19)$ e $53 \%(10 / 19)$, respectivamente. Uma pequena minoria, 16\% (3/19), tinha concluído o ensino médio.

A maioria das residências do estudo estava localizada em zona urbana (74\%) e todas se situavam em áreas periféricas.

\section{Particularidades quanto à criação do sagui (Callithrix jacchus)}

Mais da metade das habitações, 11/19 (57,9\%), mantinha os saguis (C. jacchus) somente em domicílio, enquanto 36,8\% (7/19) mantinham em semidomicilio. Dentre as residências, $1 / 19(5,3 \%)$ mantinha saguis tanto de forma domiciliada quanto semidomiciliada.

Na Tabela 1, podemos evidenciar que dentre os saguis criados em domicílio a presença de apenas um animal foi mais frequente, sendo observada em 58,4\% (7/12) dos domicílios. A quantidade média de saguis domiciliados por residência foi de dois animais. Os participantes da pesquisa que criavam saguis no semidomícilio disseram a quantidade aproximada dos mesmos, perfazendo um total de 23 animais. A quantidade média de saguis semidomiciliados por habitação foi de três saguis. Destaca-se o caso do domicílio que mantinha os saguis de ambas as formas de criação, pois o mesmo apresentou a maior quantidade de saguis, 11 domiciliados e vários outros semidomiciliados. Possibilitando, assim, reforçar a preocupação em relação ao grande risco da transmissão de zoonoses aos habitantes por tais animais.

TABELA 1 - Distribuição da quantidade de saguis (Callithrix jacchus). e de domicílios, segundo o modo de criação dos sagüis.

\begin{tabular}{lccc}
\hline Modo de criação & $\begin{array}{c}\text { Saguis } \\
\mathbf{n}^{\mathbf{0}}\end{array}$ & $\begin{array}{c}\text { Domicílios } \\
\mathbf{n} \text { - }(\%)\end{array}$ & $\begin{array}{c}\text { Saguis } \\
\mathbf{n}^{\mathbf{0}} \text { total }\end{array}$ \\
\hline Domiciliado & 1 & $7(58,4)$ & 7 \\
& 2 & $2(16,7)$ & 4 \\
& 3 & $1(8,3)$ & 3 \\
& 4 & $1(8,3)$ & 4 \\
\hline Domiciliado e semidomiciliado & $11^{*}$ & $1(8,3)$ & 11 \\
\hline Subtotal & - & $\mathbf{1 2}(\mathbf{1 0 0 , 0})$ & $\mathbf{2 9}$ \\
\hline Semidomiciliado & Vários $^{*}$ & 7 & 23 \\
\hline Subtotal & - & $\mathbf{7}$ & $\mathbf{2 3}$ \\
\hline Total & - & $\mathbf{1 9}$ & $\mathbf{5 2}$
\end{tabular}

Fonte: Pesquisa direta.

*Os 11 animais referidos na tabela eram mantidos de forma domiciliada. O criador não soube aproximar a quantidade de saguis que mantinha em situação semidomiciliada, portanto, esses não foram contabilizados no estudo.

O tempo médio de criação dos saguis nos domicílios foi aproximadamente 10 anos.

Dentre as diversas formas de obtenção dos saguis domiciliados, a captura pelos próprios criadores foi observada com maior frequência, seguida da doação por amigos ou parentes, perfazendo $50 \%(6 / 12)$ e $25 \%$ (3/12), respectivamente.

Das diferentes formas de manutenção dos saguis domiciliados, a resposta mais observada foi em gaiola e solto, em associação, perfazendo uma porcentagem de 41,7\% (5/12). No entanto, as outras formas de manutenção, apenas em gaiola e apenas solto, também foram frequentes, obtendo-se uma porcentagem de 33,3\% (4/12) e $25 \%(3 / 12)$, respectivamente.

O tipo de alimentação fornecida aos saguis pelos criadores na maioria dos casos foi frutas combinadas com comida caseira e/ou industrializada, 73,7\% (14/19). A classificação comida caseira refere-se à alimentação a base de arroz e feijão. Já em relação à comida industrializada algumas citadas merecem destaque, como: biscoito, iogurte, pão com leite, água com açúcar e bombom.

Mais da metade (58,3\%) dos criadores de saguis domiciliados afirmou que os respectivos animais mantinham contato com outros saguis de vida livre. 
Quase todos os criadores de saguis, 16/19 (84\%), mantinham outra espécie animal em seu domicílio. Apenas 16\% (3/19) dos criadores afirmaram não possuir outro tipo de animal na residência, com a presença somente dos saguis como animais de estimação. Todos os criadores $16 / 16(100 \%)$ que afirmaram possuir outros animais de estimação, além do sagui, tinham ou cão e/ou gato como representantes, sendo observado em $50 \%(8 / 16)$ a presença de ambas as espécies.

Do total dos criadores que responderam ter outras espécies de animais em sua residência, além do sagui, 56,2\% (9/16) afirmaram que o sagui mantinha contato com esses outros animais. Desses, a maioria dos criadores referenciou que seus cães e/ou seus gatos costumavam brincar com os saguis.

Mais da metade dos criadores de saguis domiciliados, 7/12 (58\%), respondeu que o animal já havia fugido alguma vez e, o mesmo, permaneceu desaparecido por no mínimo um dia.

Depois do desaparecimento, após a chegada do sagui ao domicílio, 41,7\% (5/12) dos criadores afirmaram notar alguma alteração no animal. As alterações citadas foram trauma, tristeza e/ou fraqueza. Dois criadores referiram que o animal retornou triste e entrou em óbito pouco tempo após seu reaparecimento.

TABELA 2 - Distribuição do grau de escolaridade, segundo o conhecimento da raiva, pelos criadores de sagüi (Callithrix jacchus).

\begin{tabular}{|c|c|c|c|c|c|c|c|c|}
\hline \multirow[b]{3}{*}{ Grau de escolaridade } & \multicolumn{6}{|c|}{ Conhecimento da doença Raiva } & & \\
\hline & \multicolumn{2}{|c|}{$\operatorname{sim}$} & \multicolumn{2}{|c|}{ não } & \multicolumn{2}{|c|}{ já ouviu falar } & \multicolumn{2}{|c|}{ total } \\
\hline & abs & rel & abs & rel & abs & rel & abs & rel \\
\hline Analfabeto & 2 & 33,3 & 2 & 50,0 & 2 & 22,2 & 6 & 31,0 \\
\hline Fundamental & 1 & 16,7 & 2 & 50,0 & 7 & 77,8 & 10 & 53,0 \\
\hline Médio & 3 & 50,0 & - & 0,0 & - & 0,0 & 3 & 16,0 \\
\hline Total & 6 & 100,0 & 4 & 100,0 & 9 & 100,0 & 19 & 100,0 \\
\hline
\end{tabular}

Fonte: Pesquisa direta, abs: absoluto, rel: relativo. transmissão da raiva, mais da metade (58\%) dos criadores afirmou não conhecer a maneira como a mesma é transmitida.

A Tabela 2 apresenta a correlação do nível de escolaridade dos criadores de sagui, segundo o conhecimento da raiva. Esse cruzamento de dados permite avaliar se o nível de escolaridade dos criadores está relacionado com o conhecimento sobre a raiva. Diante dos dados observados, nota-se que o baixo nível de escolaridade interfere no conhecimento da doença, visto que dos 16 criadores, que apresentavam baixo nível de escolaridade (analfabeto ou nível fundamental incompleto), apenas 19\% (3) afirmou conhecer a raiva.
Contudo, não foi enviado material para a realização de diagnóstico laboratorial.

A ocorrência do contato entre humanos e saguis é um fator de risco de grande relevância no tocante à raiva. Dentre os criadores entrevistados, a grande maioria $(84,2 \%)$ afirmou que já teve contato com os animais. Esse fato indica quão próximos são os saguis de seus criadores (Figura 1) e a partir dessa interação aumenta a probabilidade da ocorrência de agressões e da transmissão de doenças, incluindo o vírus da raiva.

Mais da metade dos entrevistados, 11/19 (58\%), afirmou a ocorrência de agressões provocadas pelos saguis criados como animais de estimação a humanos e/ou a outra espécie animal. A maioria das agressões envolveu humanos, perfazendo um total de $73 \%$ (8/11).

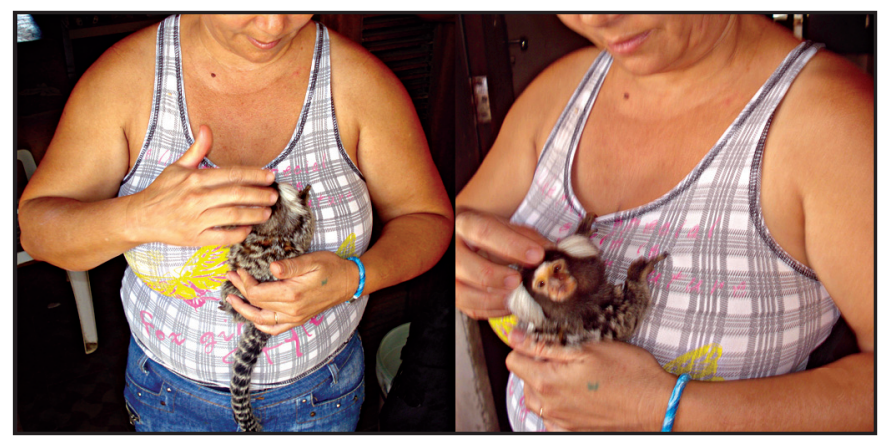

FIGURA 1 - Contato direto de um criador com o sagui (Callithrix jacchus) domiciliado.

A maioria dos indivíduos agredidos por sagui criado como animal doméstico, no Ceará, não procurou profilaxia antirrábica pósexposição, perfazendo um total de $75 \%$ (6/8). Essa falta da procura de profilaxia, provavelmente, ocorreu devido ao conhecimento limitado sobre a doença, principalmente no que diz respeito à transmissão do vírus da raiva pelos saguis.

Relativo ao conhecimento da raiva, situou-se a maioria dos criadores no conhecimento limitado da doença (68\%), 21\% afirmou não conhecer e $47 \%$ apenas ouviu falar da doença. Quanto à forma de

Por outro lado, todos os criadores (3/3), que tinham concluído o nível médio, afirmaram conhecer a doença.

A quase totalidade (94\%) dos criadores de saguis, que também possuíam cães e/ou gatos em seu domicílio, declarou levar seus animais domésticos às campanhas de vacinação antirrábica promovidas pela Secretaria de Saúde. No entanto, poucos criadores (13\%) relataram levar os saguis às campanhas de vacinação antirrábica, destinadas somente à imunização de cães e/ou gatos e afirmaram que os mesmos nunca foram vacinados.

\section{Detecção do vírus da raiva pela técnica de imunofluorescência direta}

Amostras de saliva: referente ao primeiro momento da coleta, um total de 52 amostras de saliva de saguis foram coletadas sendo destas, 29 amostras provenientes de animais domiciliados e 23 de semidomiciliados. $\mathrm{Na}$ análise pela técnica de imunofluorescência direta (IFD), todas as amostras (52/52) foram negativas para a presença de antígenos específicos do vírus da raiva. Já no segundo momento, foram novamente coletadas amostras de saliva dos 29 saguis domiciliados. Nessa ocasião, só foram coletadas amostras dos animais domiciliados devido à maior facilidade de acesso aos mesmos. Das 29 amostras analisadas, uma (3,4\%) apresentou fluorescência positiva com a presença de antígenos específicos do vírus da raiva no teste de IFD (Figura 2A).

Durante a imobilização dos saguis, para as coletas de saliva, não foi observado qualquer sintoma suspeito de raiva nos animais.

\section{Amostras de sistema nervoso central}

A partir do resultado positivo para a raiva no teste de IFD na amostra de saliva de um sagui, a respectiva residência foi novamente visitada para o recolhimento do animal. Chegando à residência, foi observado que o caso em questão estava entre 11 saguis domiciliados e, devido a impossibilidade de identificação do mesmo, todos os animais (11) foram recolhidos para a confirmação da positividade através da análise de amostras de sistema nervoso central (SNC). Das 11 amostras de SNC analisadas, 3/11 (27,3\%) apresentaram fluorescência positiva com a presença de antígenos específicos do vírus da raiva na técnica de IFD (Figura 2B). 


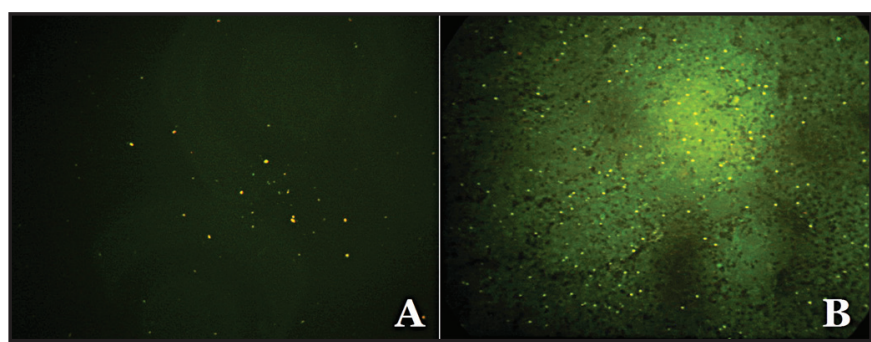

FIGURA 2 - Reações de imunofluorescência direta positivas para antígenos da raiva em amostras de saliva e SNC de sagui (Callithrix jacchus).

A: amostra de saliva, B: amostra de SNC. Objetiva 40x.

Fonte: LABOVIR - UECE, 2010

\section{DIsCUSSÃo}

A escolha da região metropolitana se deu por ser a área de maior concentração populacional do estado, sendo selecionados municípios com registro de casos de raiva silvestre ${ }^{21}$.

Nos domicílios da pesquisa, foi mais frequente a presença de três a cinco habitantes, estando de acordo com Rodrigues ${ }^{22}$, que observou uma maior frequência da criação de animais silvestres em domicílios contendo de três a cinco moradores. Mais da metade dos domicílios $10 / 19(52,6 \%)$ apresentava crianças. Os criadores de animais silvestres em cativeiro existem, provavelmente, para que seus filhos os tenham como mascote, uma vez que em habitações contendo três a cinco moradores é mais frequente a existência desses animais ${ }^{22}$.

Conforme Morais ${ }^{23}$, quanto à raiva, os acidentes envolvendo saguis ocorrem em sua maior parte na tentativa de captura no interior das matas, ou por lazer de crianças, que buscam brincar com os mesmos e acabam sendo mordidas.

Na maior parte dos domicílios, os criadores de saguis apresentavam baixo grau de instrução. Esses dados corroboram com os achados de Ferreira cols ${ }^{24}$ e Nunes $\operatorname{cols}^{25}$, que observaram que a baixa escolaridade implica no hábito da manutenção de animais silvestres em cativeiro.

Quanto à localização das residências do estudo, a maioria estava localizada em zona urbana. Esses achados estão de acordo com os resultados de Rodrigues ${ }^{22}$ onde foi observado que a maioria $(79,8 \%)$ dos domicílios que possuía animais silvestres em cativeiro estava localizada na região periférica. Com base nos resultados do presente estudo e de pesquisas realizadas ${ }^{22,26}$, pode-se inferir que os animais silvestres estão cada vez mais atingindo o perímetro urbano, ultrapassando a barreira entre zona rural e zona urbana. Assim, à medida que a urbanização desses animais vai aumentando, dificultase a classificação dos ciclos da raiva, entre urbano e silvestre.

No tocante à particularidades quanto à criação do sagui (Callithrix jacchus), a residência que mantinha saguis tanto de forma domiciliada quanto semidomiciliada mereceu destaque, devido a facilidade de contrair doenças pelos saguis dessa residência. $O$ fato dos saguis semidomiciliados viverem em vida livre e se aproximarem dos saguis domiciliados, por serem animais altamente sociáveis e estarem sempre à procura de alimento ${ }^{27}$, aumenta a probabilidade da transmissão de doenças, em destaque a raiva.

Foi evidenciada uma média de 10 anos no tempo de criação de sagüis em cativeiro no Estado do Ceará, demonstrando que essa prática não é um hábito recente no estado.

Quanto às formas de obtenção dos saguis domiciliados, a mais observada foi a captura pelos próprios criadores, corroborando com os achados de Rodrigues ${ }^{22}$ que observou que a captura de animais silvestres em Brejo Grande do Araguaia é a forma de aquisição mais frequente por criadores (57\%), mas difere dos achados de Firmino \& Seixas ${ }^{28}$, onde observaram que a maioria dos animais silvestres mantidos em cativeiro em Campo Grande foi doado (39,6\%), seguido da captura na natureza pelos seus próprios criadores $(33,2 \%)$.

Todos os criadores de saguis domiciliados do estudo estavam em desacordo com a legislação nacional de crime ambiental ${ }^{29}$, uma vez que os mesmos não possuíam licença do IBAMA para a criação dos animais e os mesmos terem sidos capturados da natureza.

Em um estudo realizado com mamíferos silvestres, mantidos em cativeiro, foi observado que $60 \%$ dos animais eram mantidos acorrentados, $20 \%$ mantidos soltos e $20 \%$ em cercados, como em gaiola $^{22}$. Nesse estudo, o índice de mamíferos silvestres presos por corrente foi mais elevado, provavelmente, devido à maioria dos mamíferos inclusos no trabalho ser de grande porte, impossibilitando ou dificultando sua manutenção em cercados.

Animais silvestres são extremamente exigentes, quando mantidos em cativeiro e para manter sua saúde em boas condições é necessário que se mimetize ao máximo o habitat de cada animal, havendo exigências específicas quanto à alimentação de cada espécie; os calitriquídeos necessitam de dieta variada e rica em proteínas ${ }^{27}$. Nota-se que os animais em questão não receberam alimentação que suprisse suas necessidades nutricionais, podendo, assim, interferir no seu comportamento. Segundo Verona \& Pissinatti ${ }^{27}$, o manejo e a alimentação de macacos e saguis em cativeiro favorece alterações comportamentais, devido a ausência de contatos sociais, bem como de variações sazonais do processo alimentar e nutricional extremamente diversificado na natureza.

$\mathrm{O}$ fato de saguis domiciliados manterem contato com sagüis que vivem em vida livre contribui para aumentar o risco de contrair doenças por esses animais, pois saguis em vida livre podem alcançar ambientes e/ou animais infectados, e sua aproximação com saguis domiciliados aumenta a probabilidade da transmissão de doenças.

Na maioria das residências do estudo, foi observada a presença do cão ou do gato como animal doméstico, além do sagui, essa questão é importante, pois cães e gatos são animais domésticos que normalmente interagem com seus donos e o contato direto desses animais com os habitantes é normalmente observado. No entanto, o contato direto também dos saguis com animais domésticos é provável de ocorrer, devido à alta sociabilidade dos saguis, provocando interações com cães e gatos, em brincadeiras, e ao potencial defensivo de todos os animais, com a possibilidade da ocorrência de mordidas, arranhaduras, entre outros, quando provocados. Nesse contexto, entra a raiva, doença transmitida principalmente pela mordedura de animais a outros animais e/ou a humanos. $\mathrm{O}$ sagui infectado com o vírus da raiva pode se tornar agressivo, se provocado ${ }^{30}$, podendo, assim, transmitir o vírus diretamente aos humanos e/ou aos seus animais domésticos.

Quando questionados por ocasião do estudo, se o sagui já havia fugido ou desaparecido do domicílio, mais da metade dos criadores de saguis respondeu que o animal já havia fugido alguma vez. Essa questão enfatiza o fato do maior risco desses animais contraírem doenças, inclusive a raiva, e transmiti-las aos humanos e/ou a seus animais domésticos. Os criadores de saguis semidomiciliados não foram inclusos nesse questionamento pelo fato desses animais rotineiramente desaparecer e reaparecer em seus domicílios. 
Segundo relato dos criadores, dois saguis foram a óbito em sua residência após desaparecimento. No entanto, nenhum material foi enviado para diagnóstico laboratorial. De acordo com a Secretaria da Saúde do Estado de São Paulo ${ }^{31}$, todos os mamíferos silvestres que morrerem ou forem encontrados mortos são suspeitos de raiva e devem ser encaminhados para diagnóstico laboratorial da raiva.

A interação entre homens e animais de estimação, baseia-se principalmente em aspectos sociais, afetivos e emocionais podendo funcionar como fator de proteção à saúde, especialmente psíquica. Contudo, os riscos existem e se materializam como zoonoses e agressões, assim, deve-se levar em consideração o equilíbrio entre os ganhos advindos dessa relação e a ocorrência de danos à saúde dos seres humanos e não-humanos ${ }^{32}$.

Os primatas não humanos são reservatórios de várias zoonoses, entre as quais a raiva, doença mortal. Um estudo realizado sobre o envolvimento de macacos em acidentes com humanos e tratamentos profiláticos para a raiva no Estado de São Paulo, mostrou que as principais espécies responsáveis por agressões foram Cebus sp. (macaco-prego) e Callithrix sp. (sagui) ${ }^{33}$.

A população, em geral, sabe que cães e gatos podem transmitir a raiva. Porém, desconhecem que morcegos, raposas, saguis e outros animais silvestres também são transmissores da doença. Por isso, ao serem mordidas por esses bichos, elas não procuram assistência médica e, assim, correm sério risco de ser vítimas da doença ${ }^{12}$.

No Brasil, foram notificados 873 casos de raiva em humanos, no período de 1980 a 1989, dos quais $4(0,5 \%)$ casos foram transmitidos por primatas; no período de 1990 a 1999 registrou-se uma significativa queda na incidência de raiva em humanos com 408 casos, dos quais $10(2,4 \%)$ casos tiveram primatas como transmissor ${ }^{34,35}$; essa queda na incidência dos casos humanos se acentuou na década de 2000 a 2009 com a notificação de 163 casos, dos quais 5 (3\%) tiveram primatas como fonte de infecçãa ${ }^{35,36}$. As espécies de primatas mais comuns nesses acidentes são a Cebus sp. (macaco-prego) e a C. jacchus. Vale salientar que o primata é a quarta principal espécie transmissora da raiva a humanos, sendo superada apenas pelo cão, morcego e gato ${ }^{34}$.

Foi questionado aos criadores sobre o conhecimento da raiva e sua forma de transmissão, observando-se um grande desconhecimento da doença pelos criadores. Diante do exposto, emerge a hipótese de não haver riscos, quanto à raiva, oriundos da convivência e interação dos humanos com saguis, sendo esta uma associação preocupante quando se imagina que os conhecimentos de um indivíduo funcionam, de fato, como um guia para a ação ${ }^{32}$. Os resultados observados nessas questões demonstram que, devido o conhecimento limitado dos criadores sobre o tema, pode haver comprometimento na tomada de decisões quanto aos cuidados com os saguis, bem como, em situações de risco, relativas à convivência com esses animais silvestres, que impliquem em sua saúde, sendo essa uma informação significativa para o trabalho.

Programas de vacinação não só do homem como também de cães e gatos mantêm o ciclo urbano da raiva sob controle. Todavia, o combate à raiva silvestre ainda é deficiente ${ }^{12}$. A vacina antirrábica de cultivo celular já foi testada em saguis, obtendo eficácia na imunização desses animais, com a produção de títulos suficientes para conferir proteção aos mesmos ${ }^{6}$. No entanto, não existe ainda no Brasil a produção de vacinas antirrábicas com a finalidade de imunizar saguis em campanhas, provavelmente, pelo fato de ser um animal silvestre proibido por lei de ser criado em ambiente doméstico e a vacinação desses animais poderia estimular esse hábito, uma vez que dessa forma os criadores estariam mais seguros quanto à profilaxia da doença envolvendo tais animais.

Quanto ao diagnóstico clínico da raiva nos animais este muitas vezes o torna-se difícil, havendo casos em que animais raivosos são considerados não-infectados, podendo também, antes dos primeiros sinais e sintomas, apresentar vírus nas glândulas salivares e serem liberados junto com a saliva, aumentando a situação de risco para seres humanos ${ }^{37}$.

A confirmação da raiva somente é feita através de diagnóstico laboratorial ${ }^{38}$. A técnica de IFD também já foi utilizada para diagnóstico laboratorial da raiva antimortem, em espécimes ricos de elementos neurais, como por exemplo, em folículos pilosos da região da nuca, mucosa bucal, esfregaços de córnea e de saliva, obtendo-se resultados positivos para antígenos da raiva ${ }^{39,40}$.

Segundo Fekadu ${ }^{41}$, a eliminação de partículas virais da raiva na saliva depende do estágio em que a doença se encontra no indivíduo, podendo esta eliminação ocorrer alguns dias antes do aparecimento da manifestação clínica, mas ocorre de forma intermitente em indivíduos aparentemente saudáveis. Em estudos realizados com amostras de saliva de animais raivosos tem-se obtido excelentes resultados positivos, através da biologia molecular, com a técnica de reação em cadeia da polimerase utilizando a enzima transcriptase reversa (RT-PCR) ${ }^{42-44}$

O teste padrão ouro, aprovado tanto pela World Health Organization (WHO), como pela Organização Internacional de Epizootias (OIE), para o diagnóstico laboratorial da raiva é o teste de IFD em amostras de tecido cerebral, realizado post-mortem ${ }^{17,37}$. Na obtenção de resultado positivo para a IFD, em amostras de saliva, faz-se necessária a investigação epidemiológica do caso suspeito, bem como, a confirmação através do teste de IFD em amostras de SNC. Segundo Kasempimolporn cols ${ }^{42}$, amostras de saliva podem ser utilizadas como uma alternativa no diagnóstico laboratorial da raiva. No entanto, é necessário um teste de confirmação do diagnóstico, devido à baixa carga viral na saliva quando comparada ao tecido cerebral e devido à eliminação de partículas virais da raiva na saliva ocorrer de forma descontínua.

\section{Conclusões}

A baixa escolaridade parece estar diretamente relacionada ao hábito de manter saguis ( $C$. jacchus) em ambiente doméstico, no Estado do Ceará. Os domicílios são locais inadequados para a criação de saguis e não propiciam bem-estar ao animal, podendo ocasionar alterações comportamentais nos mesmos. A criação de saguis em domicílio ou em semidomicílio representa risco, quanto à transmissão da raiva as pessoas e aos seus animais domésticos.

Os dados laboratoriais estão de acordo com os achados da análise dos questionários aplicados aos criadores de saguis (C. jacchus) e confirmam o risco da convivência de humanos com esses animais no Estado do Ceará.

A educação ambiental associada à educação em saúde deve ser usada como ferramentas para o desestímulo da prática da criação de saguis em cativeiro.

\section{AGRADECIMENTOS}

Agradecemos à Secretaria de Saúde do Estado do Ceará, pelo apoio técnico e de recursos humanos. 


\section{CONFLITO DE INTERESSE}

Os autores declaram não haver nenhum tipo de conflito de interesse no desenvolvimento do estudo.

\section{SUPORTE FINANCEIRO}

Coordenação de Aperfeiçoamento de Pessoal de Nível Superior (CAPES) e Fundação Cearense de Apoio ao Desenvolvimento Científico e Tecnológico (FUNCAP).

\section{REFERÊNCIAS}

1. Tordo N, Charlton K, Wandeler AI. Rhabdoviruses: Rabies. In: Collier LH, editor Microbiology and microbial infections. London: Arnold Press; 1998. p. 665-692.

2. Rolim BN, Teixeira MFS, Rolim JBS, Sousa JB. Relato do controle da raiva canina no município de Fortaleza - Ceará, no período de 2001 a 2005. Trabalho apresentado na: II Feira de Ciência, Cultura, Tecnologia e Inovação do Estado do Ceará; 19-23 junho 2006; Fortaleza, Ceará.

3. Acha PN, Szyfres B. Zoonosis y enfermedades transmissibles comunes al hombre y a los animales. $2^{\text {th }}$ ed. Washington: Organization Panamericana de la Salud; 1986. p. 502-526.

4. Kotait I, Carrieri ML, Carnieli-Junior P, Castilho JG, Oliveira RN, Macedo CI, et al. Reservatórios silvestres do vírus da raiva: um desafio para a saúde pública [Internet]. São Paulo: Secretaria Estadual de Saúde. Publicação Mensal sobre Agravos à Saúde Pública. Abril 2007. [Acesso em dezembro de 2010]. Disponível em http://www.cve.saude.sp.gov.br/agencia/bepa40_raiva.htm/.

5. Sodré MM, Gama AR, Almeida MF. Updated list of bat species positive for rabies in Brazil. Rev Inst Med Trop São Paulo 2010; 52:75-81.

6. Andrade MCR, Oliveira AN, Romijn PC, Kimura LMS. Immune response produced by rabies vaccines in marmosets (Callithrix $s p$ ). Rev Soc Bras Med Trop 1999; 32:533-540.

7. Sá LRM. Síndrome do Emagrecimento Progressivo dos Calitriquídeos Processo de Má Absorção Semelhante à Doença Celica Humana, Caracterização Clínica Laboratorial e Anatomopatológica [Tese de doutorado]. [São Paulo]: Universidade de São Paulo; 2004. 162 p.

8. Fowler ME. Zoo and wild animal medicine. Philadelphia: WB Saunders Company; 1986.

9. Favoretto SR, Mattos CC, Morais NB, Araújo FAA, Mattos CA. Rabies in marmosets, Ceara, Brazil - Callithrix jacchus - Dispatches. Emerg Infect Dis 2001; 7:1062-1065.

10. Secretaria de Saúde do Estado do Ceará. Evite contato com animais silvestres. Soins transmitem raiva [Internet]. Novembro 2010 [Acesso dezembro 2010]. Disponível em: http://www.saude.ce.gov.br/site/index.php?option=com_co ntent\&view=article \&id=1060:evite-contato-com-animais-silvestres-soinstransmitem-raiva\&catid=14:lista-de-noticias\&Itemid=248/.

11. Favoretto SR, Mattos CC, Morais NB, Carrieri ML, Rolim BN, Silva LM, et al. Rabies Virus Maintained by Dogs in Humans and Terrestrial Wildlife, Ceará State, Brazil. Emerg Infect Dis 2006; 12:1978- 981.

12. Morais NB, Romijn PC. Doenças emergentes [Internet]. Agência Fundação Oswaldo Cruz de Notícias, Saúde e Ciência para todos. Julho 2004 [Acesso maio 2010]. Disponível em: http://www.fiocruz.br/ccs/cgi/cgilua.exe/sys/ start.htm?infoid $=1003 \&$ sid $=12 /$.

13. Secretaria da Saúde do Estado do Ceará. Boletim de Cadastro de Criadores de Animais Silvestres no Ceará. Fortaleza: Governo do Estado do Ceará; 2008.

14. Marconi MA, Lakatos EM. Técnicas de pesquisa: planejamento e execução de pesquisas, amostragens e técnicas de pesquisa, elaboração, análise e interpretação de dados. São Paulo: Atlas; 2006.

15. Heard DJ, Flecknell PA. Chemical restraint/ anesthetic/analgesic agents used in primates. In: Carpenter JW, editor. Exotic Animal Formulary. $3^{\text {th }}$ ed. St Louis: MO Elsevier Saunders; 2005. p. 508-509.

16. Comissão Técnica de Biossegurança. Fundação Oswaldo Cruz. Procedimentos para a manipulação de microorganismos patogênicos e/ou recombinantes na FIOCRUZ. Rio de Janeiro: Fundação Oswaldo Cruz; 2005.
17. Dean DJ, Abelset MK, Atanasiu P. The fluorescent antibody test. In: Meslin FX, Kaplan MM, Koprowski H, editores. Laboratory Techniques in Rabies. $4^{\text {th }}$ ed. Geneva: World Health Organization; 1996. p. 88-95.

18. Roehe PM, Schaefer R, Pereira AS. Otimização da imunofluorescência direta para diagnóstico de raiva. Acta Sci Vet 2002; 30:53-57.

19. Rouquayrol MZ, Almeida Filho N. Epidemiologia \& Saúde. Rio de Janeiro: MEDSI; 2003.

20. Ministério da Saúde. Resolução 196/96 sobre pesquisa envolvendo seres humanos. Brasília: Conselho Nacional de Saúde. Comissão Nacional de Ética em Pesquisa; 1996.

21. Romijn PC. Análise da epidemiologia e desenvolvimento educacional para o controle da raiva Silvestre no Estado do Ceará. Fortaleza (CE): Secretaria de Ciência, Tecnologia e Insumos Estratégicos; 2008. p. 1-6.

22. Rodrigues PHM. Levantamento da Fauna Silvestre Mantida em Cativeiro na cidade de Brejo Grande do Araguaia, Pará: Perfil dos Criadores e Caracterização das formas de criação [Internet]. Brejo Grande do Araguaia (PA): Museu Paraense Emílio Goeldi; 2006 [atualizado 14 outubro 2008; citado maio 2010]; Disponível em: http://marte.museu-goeldi.br/marcioayres/paginas/ download/1_ens_medio_2006.pdf/.

23. Morais NB. Proteção oferecida por vacina antirrábica humana contra uma cepa dos vírus da raiva isolado de primatas calitriquídeos no Estado do Ceará - Brasil [Dissertação de mestrado]. [Fortaleza]: Universidade Estadual do Ceará; 2003. 99 p.

24. Ferreira DSS, Campos CEC, Sá-Oliveira JC, Araújo AS. Atividades de Caça de Animais Silvestres no Assentamento Rural Nova Canaã, Amapá, Brasil. Trabalho apresentado no: VII Congresso de Ecologia do Brasil; 2007 23-28 setembro. Caxambu, MG.

25. Nunes LPS, Almeida FC, Campos DS, Costa MS, Cantanhed AM, Nunes JL. Levantamento dos animais de xerimbabo do município de Chapadinha. Trabalho apresentado na: II Semana Acadêmica de Ciências Biológicas da Universidade Federal do Maranhão; 2009 junho. Chapadinha, MA.

26. Zago DC. Animais da fauna silvestre mantidos como animais de estimação [Monografia de especialização]. [Rio Grande do Sul]: Universidade Federal de Santa Maria; 2008. 39 p.

27. Verona CES, Pissinatti A. Primates - Primatas do Novo Mundo. In: Cubas SZ Silvan JCR, Catão-Dias JL, editores. Tratado de Animais Selvagens - Medicina Veterinária. São Paulo: ROCA; 2006. p.378-401.

28. Firmino MAS, Seixas GHF. O Tráfico de Animais Silvestres no Pantanal de Mato Grosso do Sul: caracterização e recomendações [Internet]. Agência Nacional de Águas; Outubro 2003 [acesso maio 2010]; 51p. Disponível em: http://www.ana. gov.br/gefap/arquivos/RE_24.pdf/.

29. Secretaria de Estado de Ciência, Tecnologia e Meio Ambiente. Leis de crimes ambientais. Belém: Secretaria de Estado de Ciência, Tecnologia e Meio Ambiente; 2002

30. Fiennes RNTW. Rabies. In: Fiennes RNTW, editor. The Pathology of Simian Primates. Part II. Karger: Basel; 1972. p. 646-662.

31. Secretaria da Saúde do Estado de São Paulo. Raiva - controle e profilaxia humana. São Paulo: Instituto Pasteur; 2003.

32. Costa EC, Bessa MS, Saraiva ERA, Coutinho MPL. Aspectos psicossociais da convivência de idosas com animais de estimação: uma interação social alternativa. Psicol: Teor Prat 2009; 11:2-15.

33. Ramos PM, Ramos PS. Acidentes humanos com macaco em relação a tratamentos profiláticos para a raiva, no Município de São Paulo, Brasil. Rev Soc Bras Med Trop 2002; 35:575-577.

34. Ministério da Saúde. Relatórios da Coordenadoria de Zoonoses e Animais Peçonhentos. Brasília: Centro Nacional de Epidemiologia. Coordenação de Controle de Zoonoses e Animais Peçonhentos; 1999.

35. Almeida FBP. Revisão bibliográfica: A Raiva e os casos em Humanos no Brasil [Monografia de especialização].[São Paulo]: Universidade Castelo Branco. 64 p.

36. Wada MY. Dez anos de raiva humana no Brasil. [Internet]. Secretaria de Vigilância em Saúde. Setembro 2010 [Acesso dezembro 2010]. Disponível em: http://www.pasteur.saude.sp.gov.br/diadaraiva/pdf/Dez_anos_de_\%20 raiva_humana_no_Brasil_MARCELO_YOSHITO_WADA.pdf/. 
37. Organização Mundial da Saúde. World Health Organization. Expert committee on rabies. $8^{\text {th }}$ Report. Series 824. Geneva: World Health Organization; 1992.

38. World Health Organization. Expert Consultation on Rabies. $1^{\text {st }}$ Report. Technical Report Series 931. Geneva: World Health Organization; 2004.

39. Koch FJ, Sagartz JW, Davidson DE. Diagnosis of human rabies by the cornea test. Am J Clin Pathol 1975; 63:509-515.

40. Zaidman GW, Billingley A. Corneal impression test for the diagnosis of acute rabies encephalitis. Ophthalmology 1998; 105:249-251.

41. Fekadu M, ShaddockJH, Baer GM. Intermittent Excretion of Rabies Virus in the Saliva of a Dog Two and Six Months after it Had Recovered from Experimental Rabies. Am J Trop Med Hyg 1981; 30:1113-1115.

42. Nagaraj T, Vasanth JP, Desai A, Kamat A, Madhusudana SN, Ravi V. Ante mortem diagnosis of human rabies using saliva samples: Comparison of real time and conventional RT-PCR techniques. J Clin Virol 2006; 36:17-23.

43. Woldehiwet $\mathrm{Z}$. Clinical laboratory advances in the detection of rabies virus. Clin Chim Acta 2005; 351:49-63.

44. Kasempimolporn S, Saengseeson W, Lumlertdacha B, Sitprija V. Detection of Rabies Virus Antigen in Dog Saliva Using a Latex Agglutination Test. J Clin Microbiol 2000; 38:3098-3099. 